\title{
Hidranencefalia bilateral em um potro híbrido: caso obstétrico
}

\section{Bilateral hydranencephaly in a hybrid foal: obstetric case}

\author{
Marcelo George Mungai Chacur ${ }^{*}$; Felipe Rydygier de Ruediger ${ }^{2}$; \\ Leticia Prestes Yamasaki ${ }^{3}$
}

\begin{abstract}
Resumo
A hidranencefalia é rara na espécie equina, a qual se caracteriza como uma malformação congênita onde, por infecções virais ou obstruções da artéria carótida, ocorre uma degeneração dos hemisférios cerebrais que se tornam uma membrana translúcida que armazena o liquido cefalorraquidiano, juntamente com o aumento e deformação óssea do crânio devido a grande coleção líquida. Devido à desproporção materno-fetal, entre a pelve da mãe e a cabeça do feto, geralmente ocorre distocia de origem fetal que na maioria dos casos, quando o feto se encontra em óbito é solucionada por meio de fetotomia com corte do crânio. Por ser um evento raro na espécie equina com limitado número de publicações sobre o assunto, o objetivo do presente relato de caso é de descrever macroscopicamente a alteração óssea do crânio e do seu conteúdo perante a hidranencefalia bilateral em um potro hibrido, produto de parto distócico de uma égua da raça Quarto de Milha acasalada com jumento, atendido no Setor de Reprodução Animal em um Hospital Veterinário Escola pertencente a uma Universidade do Oeste do estado de São Paulo. Palavras-chave: Potro híbrido, distocia fetal, hidranencefalia, fetotomia
\end{abstract}

\begin{abstract}
The hydranencephaly is rare in equine species, which is characterized as a congenital malformation where, by viral infections or obstruction of the carotid artery, there is degeneration of the cerebral hemispheres which become translucent membrane that stores the cerebrospinal fluid together with the increase and bone skull deformation due to large fluid collection. Due to the maternal-fetal disproportion between the pelvis of the mother and the fetal head, usually of fetal origin dystocia occurs in most cases when the fetus is in death is resolved through fetotomy with cutting the skull. Because it is a rare event in the equine species with a limited number of papers on the subject, the purpose of this case report is to describe the macroscopic changes in bone of the skull and its contents of the bilateral hydranencephaly in a hybrid foal, product delivered of a dystocic Quarter Horse mare mated with a donkey, served in the Department of Animal Reproduction at a Veterinary School Hospital belonging to a University of the West of São Paulo.
\end{abstract}

Key words: Hybrid foal, fetal distocy, hydranencephaly, fetotomy

\footnotetext{
${ }^{1}$ Prof. Dr., Reprodução Animal, Universidade do Oeste Paulista, UNOESTE, Presidente Prudente, SP. E-mail: chacur@unoeste.br

2 Discente do Mestrado em Ciência Animal, UNOESTE, Presidente Prudente, SP. E-mail: f_rydygier@hotmail.com

${ }^{3}$ Prof $^{\mathrm{a}}$ Dr$^{\mathrm{a}}$, Patologia Veterinária, UNOESTE, Presidente Prudente, SP. E-mail: lprestes@unoeste.br

* Autor para correspondência
} 


\section{Introdução}

As malformações do sistema nervoso central (SNC) são comuns nos animais domésticos, ocorrendo uma variedade de defeitos bem maior que em outros sistemas ou tecidos. Tem sido demonstrado que os agentes teratogênicos levam a defeitos congênitos com muito maior frequência no SNC, provavelmente em função do alto grau de diferenciação e complexidade que aumenta a susceptibilidade ao desenvolvimento desses distúrbios (MAXIE; YOUSSEF, 2007).

Hidranencefalia é uma malformação congênita e severa do cérebro, onde os hemisférios cerebrais estão totalmente ausentes, substituídos por um fluido envolto por um saco, esta se difere da hidrocefalia justamente pela ausência do cérebro (MERZ, 1999).

A hidranencefalia, já descrita em várias espécies, é um tipo de hidrocefalia compensatória (normotensiva) que se desenvolve, normalmente, em decorrência de infecção viral ou por outro agente infeccioso uterino como, por exemplo, os da família arbovírus. O líquido cefalorraquidiano fica retido em locais onde o tecido cerebral tenha sido lesionado ou inflamado, e normalmente não há aumento na pressão do líquido cefalorraquidiano (MORAES et al., 2012).

Casos de hidranencefalia são descritos em humanos, gatos, cordeiros e bovinos, sendo que em humanos a etiologia pode estar relacionada à isquemia durante a gestação, e em ruminantes à infecções virais no primeiro ou início do segundo trimestre de gestação por arbovirus, parvovirus ou pestivirus. Quando a infecção ocorre no início da gestação, pode sobrevir abortamento e no final, desenvolvimento normal do sistema nervoso central, ou formação de pequenas cavidades císticas (porencefalia). Ainda, em cordeiros a hidranencefalia pode estar relacionada à deficiência de cobre (MORAES et al., 2012).

Essa infecção ocorre num período crítico da gestação e produz zonas de necrose nos hemisférios cerebrais em desenvolvimento. Essas áreas envolvem os neuroblastos e sua migração resulta na cavitação pela ausência de neurônios no córtex. Fatores mecânicos também contribuem para o desenvolvimento de hidranencefalia. Ocorre expansão compensatória dos ventrículos laterais (hidrocefalia ex-vacuo) secundária a perda do tecido cerebral (MAXIE; YOUSSEF, 2007).

$\mathrm{Na}$ medicina humana, numerosas causas de hidranencefalia têm sido propostas, mas um compromisso primário vascular representa a teoria prevalecente (BAIKER et al., 2010).

Se não há um grande aumento do crânio, a hidranencefalia é de difícil diagnóstico e pode ser confundida com outras doenças neurológicas cabíveis aos potros. Os métodos de diagnostico por imagens atuais nos fornecem ótimas possibilidades para examinar o cérebro do potro (OEY et al., 2011).

Em um estudo retrospectivo, hidrocefalia ou hidranencefalia ocorrem em $3 \%$ dos potros que morrem ou são eutanasiados (FRAZER, 2007).

Anormalidades estruturais do feto assim como a hidranencefalia podem resultar em distocia. $\mathrm{O}$ aumento da cabeça causa desproporção entre a pelve e a cabeça. Esta condição é incompatível com a vida. O liquido cranial pode ser drenado com uma agulha ou incisão para facilitar a extração do feto (BLANCHARD et al., 2003).

Outros cortes diferentes podem ser necessários em casos de hidranencefalia onde a cabeça deve ser seccionada antes de sua remoção (FRAZER, 2007).

A ocorrência dessa enfermidade em equinos é considerada escassa, havendo raros relatos e informações sobre a sua fisiopatologia na literatura. Desta forma, o objetivo do presente relato é de descrever um caso de hidranencefalia em potro atendido em um Hospital Veterinário Escola.

\section{Relato do Caso}

Foi encaminhada ao Setor de Reprodução 
Animal do Hospital Veterinário Escola da Universidade do Oeste Paulista (UNOESTE), Presidente Prudente-SP, uma égua da raça Quarto de Milha com 42 meses de idade pesando $470 \mathrm{~kg}$, primípara, acasalada com jumento.

$\mathrm{Na}$ anamnese, o proprietário do animal relatou que o mesmo se encontrava em trabalho de parto há 4 horas. No exame clínico os seguintes parâmetros foram aferidos: frequência cardíaca (62 bpm), frequência respiratória $(38 \mathrm{mpm})$, temperatura retal $38,7^{\circ} \mathrm{C}$, tempo de preenchimento capilar de 3 segundos.

Para realização do exame obstétrico por via vaginal foi realizada anestesia epidural baixa com $7 \mathrm{~mL}$ de lidocaína 2\% sem vasoconstritor. A região perineal foi lavada com água e sabão, iniciando-se o exame obstétrico após lubrificação da via fetal mole para o diagnóstico da estática fetal: apresentação longitudinal anterior, posição superior e atitude fetal com desvio lateral direito da cabeça e pescoço.

Foi constatado o óbito do feto, se optou pela fetotomia com fetótomo modelo Thygesen e fio serra de aço (Liess) para a amputação na região atlanto-occipital, permitindo a retirada da cabeça, após o corte longitudinal mediano da mesma, seguindo a retirada do corpo do feto.

Após a fetotomia foram realizadas aplicações de 40UI de ocitocina por via intravenosa a cada 30 minutos, totalizando 4 aplicações, até a expulsão da placenta, lavagens uterinas durante 7 dias, duas vezes ao dia com água destilada a $37^{\circ} \mathrm{C}$ até o conteúdo líquido retornar límpido. Foi administrado flunixin meglumine $(1,1 \mathrm{mg} / \mathrm{kg})$ durante 5 dias, realizada a antibioticoterapia com Ceftiofur $(5 \mathrm{mg} /$ $\mathrm{kg}$ ) durante 7 dias.

\section{Resultados e Discussão}

No presente relato, o diagnóstico de hidranencefalia foi construído por meio da inspeção macroscópica do crânio do feto, no qual se evidenciou a presença de ossos delgados e flexíveis com formação incompleta na região dorsal e aumento do volume da caixa craniana, com $18 \mathrm{~cm}$ no eixo dorso-ventral (Figura 1). A ausência de massa encefálica e a presença de uma fina membrana translúcida que revestia internamente o crânio estão ilustradas na Figura 2.

Ribeiro, Galina e Sato (1982) descreveram a hidranencefalia em crianças, caracterizada por transluminação anormal do crânio devido seu conteúdo ser predominantemente líquido. Nessas circunstâncias o córtex está em sua totalidade ou em sua maior parte, reduzido a uma membrana translúcida.

Figura 1. Cabeça de potro com hidranencefalia, presença de ossos delgados e flexíveis com formação incompleta.

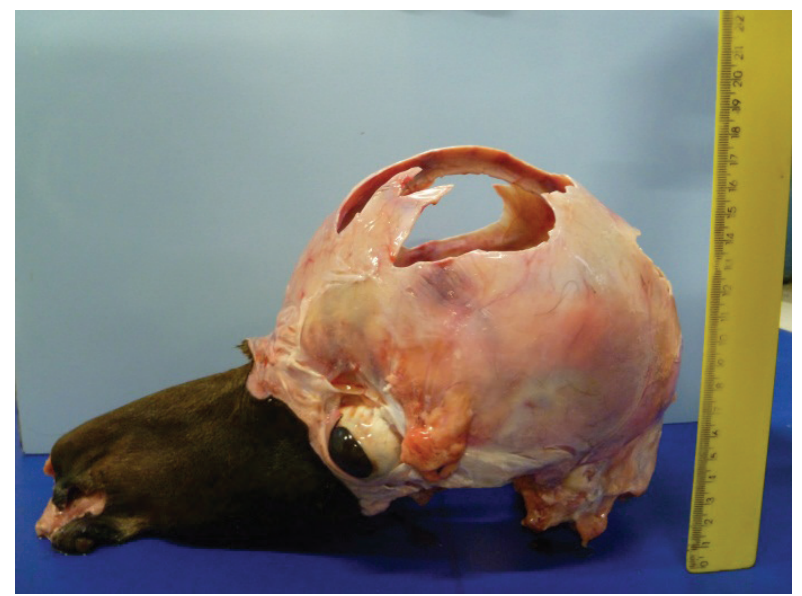

Fonte: Elaboração dos autores. 
Figura 2. Membrana cortical translúcida preenchida por líquido a qual envolvia o interior da caixa craniana do potro.

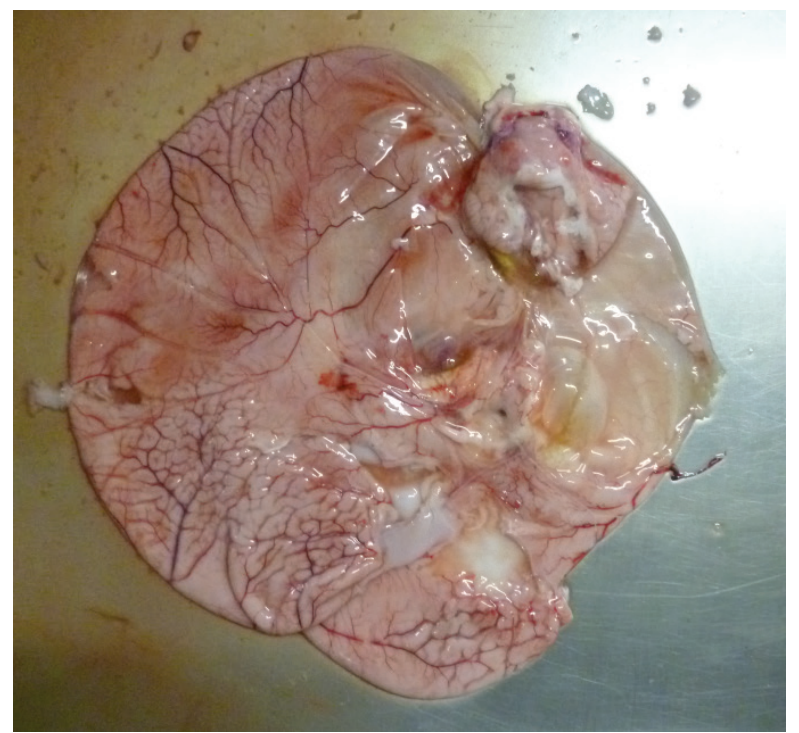

Fonte: Elaboração dos autores.

Em estudo para investigar e classificar as malformações intracranianas em ovinos por inoculação viral, Barlow (1980) identificou que nos casos de hidranencefalia, os lóbulos cerebrais ou a maior parte do cérebro eram representados por uma bolsa líquida flutuante envolta por uma fina membrana, composta histologicamente de elementos residuais corticais e das células da glia, ligada às meninges que frequentemente colapsavam após remoção do feto. No presente caso relatado, essas observações descritas por Barlow em 1980 estavam presentes.

Nos animais, a lesão se desenvolve nos estágios iniciais da vida fetal e antes da organização completa do córtex estar presente. O tecido residual cortical é liso, delimitado por células ependimárias, mas frequentemente o tecido cortical termina sem uma delimitação, exceto por uma astrocitose discreta. $\mathrm{Na}$ hidranencefalia, diferentes graus de falha no desenvolvimento do telencéfalo estão presentes, principalmente do neopalium (giros e sulcos cerebrais). Ocorre a quase completa destruição e perda do desenvolvimento do neocórtex, podendo atingir o paleopallium (componentes olfatórios) e arqchipallium: hipocampo, córtex do lobo piriforme (MAYHEW, 1989).

Com relação à ocorrência, a hidranencefalia acomete todas as espécies domésticas, sendo mais comum em bovinos, nos quais se apresenta esporadicamente ou como pequenas epizootias. A doença está associada à infecção do feto por certos vírus em um estágio crítico da gestação e nesses casos ocorre um conjunto de lesões neurais, cuja expressão depende da idade do feto no momento da infecção (MAXIE; YOUSSEF, 2007).

Várias afecções maternas têm sido responsabilizadas pela hidranencefalia durante a gestação. Esses processos podem ser de origem infecciosa, como sífilis, toxoplasmose, listeriose, hepatite infecciosa e influenza; de origem tóxica, como envenenamentos pelo monóxido de carbono; de origem traumática, nas tentativas de abortamento mediante meios mecânicos. A insuficiência vascular carotidea, na fase embrionária constitui respeitável justificativa para as anormalidades observadas já que, freqüentemente encontramos hipoplasia do referido sistema, enquanto que as do sistema vertebro-basilar apresentam aspecto normal. Por outro lado, as artérias cerebrais posteriores podem faltar, mas, quando presentes, nutrem porções malformadas de tecido nervoso nos lobos temporais e occipitais. A reprodução experimental da hidranencefalia unilateral pode ser obtida através da embolização parafinica das carótidas em embriões de animais domésticos e, também pela ligadura das artérias carótidas e veias jugulares em embriões de macacos. (RIBEIRO; GALLINA; SATO, 1982).

Hidranencefalia tem sido relatada em bebes humanos, gatos, cordeiros e vitelos. Os casos humanos são pensados para ter uma base primária isquêmica com comprometimento vascular que ocorre durante a gestação enquanto os casos em animais estão intimamente associados com infecções virais durante a prenhez, que ocorre no primeiro ou início do segundo trimestre (principalmente 
arboviroses, como Akabane vírus, vírus da língua azul, febre do vale do Rift e vírus Wesselsbron; e também parvovirose ou pestivirus, tais como o vírus da diarréia viral bovina e o vírus da doença de Fronteiras). Embora um efeito citopático viral direto no cérebro fetal é considerado provável por essas infecções, lesão vascular possível contribuindo para a destruição cerebral não é excluída. Na literatura consultada, um relato anterior foi publicado como hidranencefalia ocorrendo em um potro, como parte de uma malformação, complexo esporádica incluindo microcefalia, aplasia cerebelar, schisis mesencefálica e myeloschisis (BAIKER et al., 2010).

A matriz sub-ependimal germinal do cérebro em desenvolvimento é uma zona altamente celular em que a mitose ativa ocorre e é, portanto, sensivel à isquemia devido ao estroma escasso, vasculatura delicada e metabolismo elevado (FRAZER, 2007).

Hidranencefalia bilateral foi produzida experimentalmente em fetos ovinos por ligação de ambas as artérias carótidas durante 2 semanas, aos 100 dias de gestação (WINTOUR et al., 1996). Mesmo que os cérebros fetais ovinos continuaram a ser perfundidos através da anastomose vertebraloccipital, a taxa de fluxo de sangue cerebral foi significativamente reduzida. Alguns investigadores propuseram que hidranencefalia viral induzida não é causada pelo efeito direto citopático do vírus, mas por um compromisso patológico dentro dos sistemas vasculares fetais (BAIKER et al., 2010).

Nas formas mais graves de hidrocefalia existe um enfraquecimento dos ossos cranianos, facilitando a compressão do crânio, de modo a permitir o parto vaginal. Quando isto não pode ser feito, a cúpula do crânio pode ser cortada por fetótomo. Se o feto é decapitado existe ainda a dificuldade de transportar a cabeça (ARTHUR; NOAKES; PEARSON, 1989).

Os monstros fetais são menos comuns nas éguas do que nas vacas, mas sua presença deve ser suspeita se o parto não ocorre como devido.
Casos de hidrocefalia com grande aumento do crânio vêm sendo reportados. A cabeça deformada geralmente é muito grande para passar pela pelve. Anquilose de uma ou mais articulações interferem no nascimento dificultando a manipulação da articulação pelo veterinário (FRAZER, 2007).

A alta incidência de desvio lateral de cabeça e pescoço também foi encontrada sendo a fetotomia uma alternativa para essa distocia equina (FRAZER, 2007).

\section{Conclusão}

Por ser um evento raro, a hidranencefalia não está elucidada em relação às suas causas. A despeito disso, trata-se de uma intercorrência diagnosticada durante $\mathrm{o}$ atendimento obstétrico em partos distócicos, podendo levar à complicações para a parturiente.

\section{Referências}

ARTHUR, G. H.; NOAKES, D. E.; PEARSON, $\mathrm{H}$. Veterinary reproduction and obstetrics. 6. ed. Philadelphia: Bailliére Tindall, 1989. 1005 p.

BAIKER, K.; SAUNDERS, N.; SUMMERS, B. A.; PIERCY, R. J.; SMITH, K. Hydranencephaly in a foal Equine Veterinary Education. Wiley, New Jersey, v. 22, n. 12, p. 593-598, 2010.

BARLOW, R. M. Morphogenesis of hydranencephaly and other intracranial malformations in progeny of pregnant ewes infected with pestiviruses. Journal of Comparative Pathology, Philadelphia, v. 90, n. 1, p. 8798, 1980.

BLANCHARD, T. L.; VARNER, D. D.; SCHUMACHER, V.; LOVE, C. C.; BRINSKO, S. P.; RIGBY, S. Manual of equine reproduction. 2. ed. Philadelphia: Elsevier, 2003. $336 \mathrm{p}$.

FRAZER, G. S. Dystocia and fetotomy. In: SAMPER, J. C.; PYCOCK, J. F.; McKINNON, A. O. Current therapy in equine reproduction. Philadelphia: Saunders, 2007. p. 417-434.

MAXIE, M. G.; YOUSSEF, S. Nervous system. In: MAXIE, M. G. Pathology of domestic animals. Philadelphia: Saunders, 2007. v. 1, p. 281-457. 
MAYHEW, I. G. Large animal neurology. Philadelphia: Lea \& Febiger, 1989. 380 p.

MERZ, E. Three-dimensional transvaginal ultrasound in gynecological diagnosis. Ultrasound Obstet Gynecol, Wiley, v. 14, n. 1, p. 81-86, 1999.

MORAES, C. N.; MAIA, L.; SIMON, B. B. Z.; BICUDO, L. C.; SILVA, Y, F. R. S.; OLIVEIRA, I. R. S.; MEIRA, C. Hidranencefalia em feto equino - relato de caso. Veterinária e Zootecnia, Botucatu, v. 19, n. 3, p. 314-317, 2012.
OEY, L.; MULLER, J. M. V.; KLOPMANN, T.; JACOBSEN, B.; BEINEKE, A.; FEIGE, K. Diagnose eines internen und externen Hydrozephalus bei einem Warmblut - fohlen mittels Magnetresonanztomographie. Tierärztl Praxis Grobtiere, v. 39, n. 1, p. 41-45, 2011.

RIBEIRO, M. V. M.; GALliNA, R. A.; SATO, T. Hidranencefalia. Arquivo de Neuro-Psiquiatria, São Paulo, v. 40, n. 2, p. 184-192, 1982.

WINTOUR, E. M.; LEWITT, M.; MCFARLANE, A.; MORITZ, K.; POTOCNIK, S.; REES, S.; TANGALAKIS, K. Experimental hydranencephaly in the ovine fetus. Acta Neuropathol, New York, v. 91, n. 5, p. 537-544, 1996. 